\title{
The Evolution of Per-cell Organelle Number
}

\author{
Logan W. Cole* \\ Department of Biology, Indiana University, Bloomington, IN, USA
}

Organelles with their own distinct genomes, such as plastids and mitochondria, are found in most eukaryotic cells. As these organelles and their host cells have evolved, the partitioning of metabolic processes and the encoding of interacting gene products have created an obligate codependence. This relationship has played a role in shaping the number of organelles in cells through evolution. Factors such as stochastic evolutionary forces acting on genes involved in organelle biogenesis, organelle-nuclear gene interactions, and physical limitations may, to varying degrees, dictate the selective constraint that per-cell organelle number is under. In particular, coordination between nuclear and organellar gene expression may be important in maintaining gene product stoichiometry, which may have a significant role in constraining the evolution of this trait.

Keywords: plastid, mitochondria, stoichiometry, organelle biogenesis, evolutionary cell biology

\section{OPEN ACCESS}

Edited by:

Alessandro Minelli,

University of Padua, Italy

Reviewed by:

Jordan Okie,

Arizona State University, USA

Pedro Martinez,

University of Barcelona, Spain

*Correspondence:

Logan W. Cole

Iwcole@indiana.edu

Specialty section:

This article was submitted to Evolutionary Developmental Biology,

a section of the journal

Frontiers in Cell and Developmental

Biology

Received: 08 June 2016

Accepted: 04 August 2016

Published: 18 August 2016

Citation:

Cole LW (2016) The Evolution of Per-cell Organelle Number.

Front. Cell Dev. Biol. 4:85.

doi: 10.3389/fcell.2016.00085

\section{INTRODUCTION}

With a few exceptions (Cavalier-Smith, 1987; Karnkowska et al., 2016), mitochondria or plastids are found in all eukaryotic cells. As these organelles and their host cells have evolved together, the partitioning of metabolic processes and the encoding of interacting gene products have created an obligate codependence. This relationship has obviously played an important role in shaping the genomes of these different compartments (Howe et al., 2002; Adams and Palmer, 2003), but what has not been widely considered is how this intimate relationship has constrained the number of organelles in a cell through evolution.

Typically, a multicellular eukaryote has hundreds or thousands of these organelles in each of their cells. These numbers not only vary among species but also among tissue types (Veltri et al., 1990; Li et al., 2001; Moller, 2004) and temporally during the cell cycle, across development, and in response to stress (Holloszy, 1967; Posakony et al., 1977; Boffey and Leech, 1982; Visser et al., 1995; Moller, 2004; Kowald and Kirkwood, 2011). These organelles serve necessary metabolic functions and create gene products that are necessary not only for their own function but for that of the entire cell. This, along with the transfer of genes from the organelle to nuclear genomes over evolutionary time (Blanchard and Schmidt, 1995; Howe et al., 2002; Adams and Palmer, 2003), has created a necessary coordination between these entities. These factors, to some extent, have constrained the number of organelles in a cell through selection. Other factors, such as stochastic evolutionary forces, which vary depending on the population genetic environment of the genes involved in organelle biogenesis and organelle-nuclear interactions, or physical limitations may obscure the selective constraint that this feature is under.

\section{ESTIMATING ORGANELLE NUMBER ACROSS THE EUKARYOTES}

Organelles can be counted directly using molecular staining (Williamson and Fennell, 1979; Chazotte, 2011) and microscopy, but this is very labor intensive. Alternatively, organelles can 
be quantified with some uncertainty through flow cytometry (Mattiasson, 2004), which has the drawback of underestimation that results from the isolation process, or through the use of biochemical probes (Robin and Wong, 1988). Recently, some have been using micro-dissection to estimate organelle number by extrapolating counts from cross sections (Inuda and Wildermuth, 2004; Kubinova et al., 2014). Some would argue that the methods that involve direct counting are the only ones appropriate to properly estimate the number of organelles in a cell, but they are impractical when it comes to some cases, such as animal cells, that have thousands of mitochondria.

These techniques are useful for low error quantification of organelle number within a cell but, with the advent of sequencing technology, one can use organelle genome copy number to estimate organelle number (Moraes, 2001). This, of course, comes with the consideration that there tends to be between 1 and 10 copies of mtDNA per mitochondrion in animals (Satoh and Kuroiwa, 1991; Weisner et al., 1992; Bereiter-Hahn and Voth, 1996; Iborra et al., 2004; Legros et al., 2004; Brown et al., 2011; Kukat et al., 2011), between 50 and 200 copies of mtDNA in yeast (Williamson and Fennell, 1979; Azpiroz and Butow, 1993; Solieri, 2010), and between 0 and 2 copies of mtDNA in plants (Suyama and Bonner, 1966; Bendich and Gauriloff, 1984; Preuten et al., 2010), though this estimate may be influenced by the presence of substoichiometric mtDNA molecules (Palmer and Shields, 1984; Preuten et al., 2010; Mower et al., 2012), and up to $\sim 1000$ copies of cpDNA per mature chloroplast (Boffey and Leech, 1982). These per-organelle genome copy numbers can also vary temporally; they can either change over the life span of the organelle as is the case with most chloroplasts (Lamppa et al., 1980; Scott and Possingham, 1980, 1983; Baumgartner et al., 1989; Kuroiwa, 1991), the lifespan of the organism as is the case with some mitochondria (Hartmann et al., 2011) and chloroplasts (Zoschke et al., 2007), or change erratically and unpredictably due to the unequal redistribution of nucleoid material between organelles during fusion and fission, which has been shown to be the case in some mitochondria (Arimura et al., 2004a).

A major caveat with these methods of quantification is that they tend to estimate organelle number at a particular time point or over a very small time range, while it is known that the number of organelles is a very labile trait that can vary a great deal over time (Stoecker and Silver, 1990; Arimura et al., 2004a).

Like many unicellular eukaryotes, which can have as few as a single mitochondrion or a few dozen mitochondria per-cell (Gray et al., 2004) and can also have on the order of $10^{5}$ mitochondria (Okie et al., 2016), multicellular eukaryotes tend to have a wide range of per-cell mitochondria numbers with estimates in mammalian somatic cells ranging from $\sim 80$ to $\sim 2000$ (Robin and Wong, 1988; Bogenhagen, 2011; Kukat et al., 2011) and from $\sim 200$ to $\sim 600$ in plant mesophyll cells (Logan, 2007). Yeast have been shown to vary in terms of per-cell mitochondria number based on substrate despite relatively consistent per-cell mtDNA copy number-for example, yeast grown on a glucose substrate were shown to contain 2-3 mitochondria that are branched in structure while those grown on an ethanol substrate contain 20-30 tubular-shaped mitochondria (Visser et al., 1995). Occasionally, there can be tens of thousands (Satoh and Kuroiwa,
1991) or even millions of mitochondria in an animal oocytes, as is the case in the oocytes of Xenopus laevis, which have been estimated to have on the order of $10^{7}$ mitochondria (Marinos, 1985). Mitochondria are very dynamic entities that are subject to frequent fusion and fission (Arimura et al., 2004a; Kowald and Kirkwood, 2011) so this can change over time. Both mitochondria (Gurdon et al., 2016) and chloroplasts (Thyssen et al., 2012) have been shown to move between cells in plants, even among those of different species, which may have some effect on per-cell counts of organelles. Some unicellular algae will tend to have a single chloroplast (Itoh et al., 1996) whereas some cells from plants, such as mesophyll cells, have been seen to have an average of $\sim 50$ chloroplasts at their earliest stages of development (Boffey and Leech, 1982) and up to hundreds of chloroplasts (Moller, 2004) with an average of 155 at their latest stages of development (Boffey and Leech, 1982). Similarly, mitochondria number has been shown to fall $25-50 \%$ during leaf senescence in Vitis vinifera (Ruberti et al., 2014). These numbers suggest that those early eukaryotes had one or a few of these organelles, as in some modern unicellular eukaryotes, and then underwent an increase followed by a diversification in organelle number, resulting in the variation in organelle number we see among multicellular eukaryotes.

These numbers not only vary significantly across organisms, but among tissue types. For example, there are more chloroplasts in leaf tissue than in other tissue (Li et al., 2001). Moist, leafy tissue in plants has been shown to have more mitochondria than woody and stem tissue (Moller, 2004). This is the result of leafy, green tissue being the important focal tissue of photosynthesis. Mesophyll and stomata cells have also been shown to lose mitochondria at different rates during leaf senescence (Ruberti et al., 2014). Studies of the mouse have shown that tissue of the liver, kidney, heart, and brain have different numbers of mitochondria per-cell (Veltri et al., 1990). Organelle number also varies in in terms of lability across tissue types. For example, muscle cells are known to vary greatly in mitochondrial content with organismal physical activity (Holloszy, 1967). The differences in mitochondria number among tissue types may be the result of varying energetic constraints (Holloszy, 1967; Veltri et al., 1990). It has also been shown that there can be large reductions in chloroplast number in stressful high and low light conditions in a variety of green plants (Higa and Wada, 2016).

The extent to which per-cell mitochondria number varies within tissue is largely unknown. Many methods used to count mitochondria within multicellular eukaryotes involve large samples of tissue with flow cytometry or other methods that represent an aggregate of many cells within a tissue (Mattiasson, 2004). In vivo estimates would require microscopy of many cells within the same tissue of the same organism. Variability has been assessed within a HeLa cell line, which was shown to contain between 383 and 882 mitochondria per-cell (Posakony et al., 1977), though this is mostly the result of differences in cell cycle stages. Furthermore, this should not be interpreted as a reflection of natural or in vivo variation of within-tissue organelle number. Within-tissue variation in chloroplast number, however, has been shown to be rather extensive with between $\sim 2$ and $\sim 140$ fold variation in chloroplast number in palisade tissue from different 
green plants (Higa and Wada, 2016). To what extent and how within-tissue per-cell organelle number variation is maintained will require more data and this will serve as a prerequisite to analyses with methods from quantitative genetics, developmental biology, and physiology.

\section{ORGANELLE BIOGENESIS}

At the molecular level, per-cell organelle number is underpinned by series of transcriptional pathways. These processes are distinct but involve related components in chloroplasts and mitochondria that mostly control the pattern of division of organelles and the replication and transcription of their genomes. An understanding of what genes are involved in organelle biogenesis is necessary to fully understand the evolution of organelle number in cells.

The so-called "master regulators" of mitochondrial biogenesis are members of the PGC (peroxisome proliferator-activated receptor- $\gamma$ ) family of co-transcriptional regulatory factors (Irrcher et al., 2003; Ventura-Clapier et al., 2008). In particular, PGC- $1 \alpha$ is known to activate different transcription factors that interact with Tfam (mitochondrial transcription factor A), which is involved in the replication and transcription of mtDNA and the transcription of nuclear-encoded mitochondrial components (Virbasius and Scarpulla, 1994). Though the connection between PGC- $1 \alpha$ and the physical division of mitochondria is not fully understood, it has been shown to increase respiration in cells $(\mathrm{Wu}$ et al., 1999). The division of mitochondria is known to involve the dynamin-like proteins (Arimura et al., 2004b) and Fis-type proteins (Lu et al., 2011). These pathways are mostly understood from the perspective of human and mouse mitochondria, so these processes may be quite different in the mitochondria of other eukaryotes.

Plastid biogenesis is much less well-understood than mitochondrial biogenesis because many factors implicated in this process are often only known from the phenotyping of Arabidopsis mutants (López-Juez, 2007). Those factors whose functions are well-understood seem to mostly be involved in the formation of plastid division rings including dynamin-like proteins (Gao et al., 2003), like those involved in mitochondrial biogenesis. As such, the process of plastid division is mostly understood to be a mechanical one with daughter plastid components mostly being the result of random, unequal segregation of the contents of the parent cell (López-Juez, 2007), though some components of the plastid, such as thykaloids, seem to have an equitable redistribution between daughter plastids as regulated through the ARTEMIS and PEND proteins (Fulgosi et al., 2002; Terasawa and Sato, 2005).

\section{THE POPULATION GENETIC ENVIRONMENT OF GENES INVOLVED IN ORGANELLE NUMBER}

The genes involved in determining organelle number mostly fall within one of two categories: (1) those that are in the nuclear genome, including those that control the division of organelles and the over two-hundred genes that encode products that interact with organelle-encoded proteins (van Wijk, 2004; Giegé et al., 2005; van Wijk and Baginsky, 2011) and (2) those that encode proteins in the organelle genomes themselves, especially those that interact with nuclear proteins, whose potential importance will be explained later in the essay. The three compartments in which these genes reside present different population genetic environments that presumably play a large role in dictating the relative power of selection in the evolution of organelle number.

Population mutation rate (often represented by $\pi$ or $\theta$ ), which is a reflection of the population genetic environment as influenced by mutation and drift, is $2 N_{\mathrm{g}} u$ where $u$ is the mutation rate per nucleotide per generation and $N_{\mathrm{g}}$ is the effective number of genes at a locus (Lynch, 2006). For diploid nuclear genomes, this term is equal to $4 N_{\mathrm{e}} u$ where $N_{\mathrm{e}}$ is the effective population size. This is important to consider as genes that dictate organelle number, like those that regulate mitochondrial biogenesis such as the PGC family (Ventura-Clapier et al., 2008) and those that encode the dynamin-like proteins and Fis-type proteins that are involved in plastid and mitochondrial division (Gao et al., 2003; Arimura et al., 2004b; Lu et al., 2011), are encoded in the nucleus.

The argument has been made that, due to the haploidy and maternal transmission of organelles, population mutation rate is simply equal to $N_{\mathrm{e}} u$ in organelle genomes (Palumbi et al., 2001). Alternatively, it has been argued that this idea assumes an incorrect parity of selection and recombination between nuclear and organelle genomes and equivalency between males and females with respect to progeny (Lynch et al., 2006). Furthermore, organelle mutation rate is thought to vary much between different taxa. For example, when compared to nuclear genomes, animal mitochondrial mutation rates appear to be much higher (Brown et al., 1979) and plant mitochondrial mutation rates appear to be much lower (Palmer and Herbon, 1988).

Regardless of any of these considerations, the effective population size is generally thought to be smaller in organelle genomes (Palumbi et al., 2001; Lynch et al., 2006) and, as such, the strength of drift is thought to be greater than that of the nucleus, but the efficacy of selection could be just as great (Cooper et al., 2015) and vary greatly between different taxa with different mutation (Brown et al., 1979; Palmer and Herbon, 1988) and recombination regimes (Rokas et al., 2003; McCauley, 2013). As a result of these differences, for example, if organelleencoded genes are important in the determination of per-cell organelle number, the efficacy of selection on organelle number may be more so in animals than in plants because of the greater mutation rate (Brown et al., 1979; Palmer and Herbon, 1988) and lower incidence of recombination (McCauley, 2013) in animal mitochondrial genomes.

\section{METABOLISM AS A POTENTIAL SELECTIVE CONSTRAINT}

The metabolic needs of a cell and the capacity for organelles to fulfill these needs may act as selective constraints on the number of organelles in a cell. Mitochondria, for example, perform a 
few different metabolic processes, such as the production of ATP through primarily aerobic respiration, regulation of cellular metabolic processes (McBride et al., 2006), and steroid synthesis (Rossier, 2006). Chloroplasts perform photosynthesis, producing NADPH and ATP through light reactions and glucose through the Calvin cycle, and are also involved in fatty acid (Rawsthorne, 2002) and amino acid synthesis (Burgess, 1989).

Metabolic needs have been thought to drive the relationship between the total amount of mitochondria and body mass across organisms according to a power law (Kleiber, 1947). Per-cell mitochondria content is also seen to change with cell size across the cell cycle (Posakony et al., 1977). Single-celled eukaryotes do not appear to follow Kleiber's power law for mitochondria or chloroplasts, but do appear to follow linear and sublinear scaling, respectively, for organelle number with cell size (Okie et al., 2016). This study also shows that organelle size does not appear to scale strongly with cell size in single-celled eukaryotes, suggesting that per-cell organelle number is more important than organelle size as a means of modulating energetic requirements at the scale of the cell. Rafelski et al. (2012), however, did note a sublinear, positive correlation between cell volume and total organelle volume in yeast. Given the relationship between cell size and per-cell mitochondrial content, perhaps there is an optimal per-cell mitochondria number given cell size and the nature of mitochondrial biogenesis.

It may soon be possible to obtain an estimate of whole-cell energetic requirements per unit time and use this to determine the optimal per-cell mitochondrial content to further understand the role of selection on this trait through quantitative genetics. Though it is not yet possible to completely understand the energetic needs per unit time in a eukaryotic cell, there has been some progress in developing theoretical models that can estimate the metabolic and energetic needs of a single cell (Suthers et al., 2009; Karr et al., 2012; Lynch and Marinov, 2016).

\section{COORDINATION BETWEEN THE NUCLEUS AND ORGANELLES: TRANSCRIPTION AND TRANSLATION}

Since the original endosymbiosis events, there has been a substantial integration of the function of organelles and their hosts, some of which is due to the transfer of genes from organelle to nuclear genomic compartments over evolutionary time (Blanchard and Schmidt, 1995). As a result, most protein products encoded in the organelles form complexes with those that are encoded in the nucleus. There have also evolved to be nuclear-encoded transcription factors (Leigh-Brown et al., 2010) and proteins involved in post-transcriptional modification such as RNA editing (Schmitz-Linneweber and Small, 2008) that regulate the expression of mitochondrial genes. As such, some level of stoichiometric balance has to be maintained between nuclear- and organelle-encoded factors during the processes of transcription and translation to ensure the proper allocation of resources and to prevent waste in terms of energy and macromolecules. Maintenance of proper stoichiometric ratios for gene products is necessary, at least to some degree, in maintaining some semblance of physiological homeostasis at both the cellular and organismal levels.

Many mitochondrial encoded proteins (Giegé et al., 2005) and almost all plastid encoded proteins (van Wijk, 2004; van Wijk and Baginsky, 2011) form multi-subunit complexes with nuclear encoded products, of which there are about two-hundred. Among these complexes are ribosomes and ATP synthases of both organelles. Rubisco, PEP, and the major photosynthetic complexes of the plastid and all four major complexes of the electron transport chain in the mitochondrion are also among those formed by complexing with nuclear subunits. These are formed from specific stoichiometric ratios of subunits. The number of organelles could play a significant role in influencing the number of these products produced in a cell and, as such, the nuclear-organelle subunit stoichiometry could act as a significant constraint on the number of organelles in the cell.

Though levels of transcription do differ between genes, mitochondrial transcription in animals is mostly performed at a constitutive level (Bendich, 1988) because it occurs over the entire circular mitochondrial genome, one strand at a time (Lee and Clayton, 1998). This constitutive transcription and the tenuous connection between metabolic activity and gene expression in mitochondrial genomes (Bendich, 1988) suggest that, in order to maintain the appropriate numbers of transcripts, other means at other levels must be utilized by the cell. Another potential means of controlling gene product stoichiometry may be by adjusting organelle DNA copy number per organelle, but it has been shown that, since this quantity varies so little (Boffey and Leech, 1982; Weisner et al., 1992), per-cell organelle number rather than per-organelle DNA copy number is the major driver of per-cell organelle DNA copy number (Robin and Wong, 1988; Zoschke et al., 2007). Adjusting the number of organelles could act as a broad-scale blunt means of regulation for these genes, as an alternative to regulating expression on a gene-by-gene or genome-by-genome basis. As such, per-cell organelle number could play an important role in maintaining the stoichiometry between nuclear- and organelle-encoded subunits.

Given a particular cell, there could be an optimal number of organelles to maintain the stoichiometry between nuclear and organelle gene products. Counting gene products can be performed at the level of transcription by looking at the number of particular mRNAs in a cell (Itzkovitz et al., 2012) or at the level of translation by counting the number of particular proteins in a cell (Huang et al., 2004). By doing this, we could see how closely these quantities track the expected stoichiometry in some cases. Since we can estimate the number of organelles in a cell by the methods stated earlier, it may be possible to survey many cells of the same type for the density of organelles and see if there is an optimum that gives a ratio of gene products closest to the expected stoichiometric ratio.

If we can make the assumption that it is most fit for cells to produce the least amount of excess gene product for those proteins that form obligatory complexes, looking at many cells may be able to tell us which have the closest to the optimum per-cell organelle number. A comparison of the typical percell organelle density to our best estimate of the optimum percell organelle density may tell about the role of evolution in 
shaping organelle number. For example, if most cells have a farfrom-optimal organelle number per-cell, it may merit further investigation into the possibility of there being a drift barrier (Lynch, 2011) or some other, previously not understood, physical constraint that is preventing most cells from reaching this stoichiometric optimum.

\section{CONCLUSION}

Metabolism and the production of organelle encoded gene products are both important to consider in the context of organelle and cell evolution. Cells have energetic requirements and need to maintain some semblance of particular gene product quantities in order to function properly. Work in the fields of biophysics and physiology will allow us to determine how these processes are impacting fitness and constraining per-cell organelle number. To what extent these processes constrain

\section{REFERENCES}

Adams, K. L., and Palmer, J. D. (2003). Evolution of mitochondrial gene content: gene loss and transfer to the nucleus. Mol. Phylogenet. Evol. 29, 380-395. doi: 10.1016/S1055-7903(03)00194-5

Arimura, S., Aida, G. P., Fujimoto, M., Nakazono, M., and Tsutsumi, B. (2004a). Arabidopsis dynamin-like protein 2a (ADL2a), like ADL2b, is involved in plant mitochondrial division. Plant Cell Physiol. 45, 236-242. doi: 10.1093/ pcp/pch024

Arimura, S., Yamamot, J., Aida, G. P., Nakazono, M., and Tsutsumi, N. (2004b). Frequent fusion and fission of plant mitochondria with unequal nucleoid distribution. Proc. Natl. Acad. Sci. U.S.A. 101, 7805-7808. doi: 10.1073/ pnas.0401077101

Azpiroz, R., and Butow, R. A. (1993). Patterns of mitochondrial sorting in yeast zygotes. Mol. Biol. Cell. 4, 21-36. doi: 10.1091/mbc.4.1.21

Baumgartner, B. J., Rapp, J. C., and Mullet, J. E. (1989). Plastid transcription activity and DNA copy number increase early in barley chloroplast development. Plant Physiol. 89, 1011-1018. doi: 10.1104/pp.89.3.1011

Bendich, A. (1988). Why do chloroplasts and mitochondria contain so many copies of their genome? Bioessays 6, 279-282.

Bendich, A. J., and Gauriloff, L. P. (1984). Morphometric analysis of cucurbit mitochondria: the relationship between chondriome volume and DNA content. Protoplasma 119, 1-7. doi: 10.1007/BF01287811

Bereiter-Hahn, J., and Voth, M. (1996). Distribution and dynamics of mitochondrial nucleoids in animal cell in culture. Exp. Biol. 1:4.

Blanchard, J. L., and Schmidt, G. W. (1995). Pervasive migration of organellar DNA to the nucleus in plants. J. Mol. Evol. 41, 397-406. doi: 10.1007/ BF00160310

Boffey, S. A., and Leech, R. M. (1982). Chloroplast DNA levels and the control of chloroplast division in light-grown wheat leaves. Plant Physiol. 69, 1387-1391. doi: $10.1104 / p p .69 .6 .1387$

Bogenhagen, D. F. (2011). Mitochondrial DNA nucleoid structure. Biochim. Biophys. Acta 1819, 914-920. doi: 10.1016/j.bbagrm.2011.11.005

Brown, T. A., Tkachuk, A. N., Shtengel, G., Kopek, B. G., Bogenhagen, D. F., Hess, H. F., et al. (2011). Super-resolution fluorescence imaging of mammalian mitochondrial nucleiods. Mol. Cell. Biol. 31, 4994-5010. doi: 10.1128/MCB.05694-11

Brown, W. M., George, M., and Wilson, A. C. (1979). Rapid evolution of animal mitochondrial DNA. Proc. Natl. Acad. Sci. U.S.A. 76, 1967-1971. doi: 10.1073/pnas.76.4.1967

Burgess, J. (1989). An Introduction to Plant Cell Development. Cambridge: Cambridge University Press.

Cavalier-Smith, T. (1987). Eukaryotes with no mitochondria. Nature 326, 332-333. doi: $10.1038 / 326332 \mathrm{a} 0$ per-cell organelle number through selection will be more clear as the field of cell-scale proteomics becomes more empirically and computationally tractable. As these techniques become increasingly practical, we will be able to apply the analytical approaches of population and quantitative genetics to better understand this issue from an evolutionary perspective.

\section{AUTHOR CONTRIBUTIONS}

The author confirms being the sole contributor of this work and approved it for publication.

\section{ACKNOWLEDGMENTS}

I thank Mike Lynch for motivating the writing of this manuscript. I also thank Jeff Palmer and Elizabeth Skippington for their discussions on organelles.
Chazotte, B. (2011). Labeling mitochondria with MitoTracker dyes. Cold Spring Harb. Protoc. 8, 990-992. doi: 10.1101/pdb.prot5648

Cooper, B. S., Burrus, C. R., Ji, C., Hahn, M. W., and Montooth, K. L. (2015). Similar efficacies of selection shape mitochondrial and nuclear genes in both Drosophila melanogaster and Homo sapiens. G3 5, 2165-2176. doi: $10.1534 / \mathrm{g} 3.114 .016493$

Fulgosi, H., Gerdes, L., Westphal, S., Glockmann, C., and Soll, J. (2002). Cell and chloroplast division requires ARTEMIS. Proc. Natl. Acad. Sci. U.S.A. 100, 4328-4333. doi: 10.1073/pnas.172032599

Gao, H., Kadirjan-Kalbach, D., Froehlich, J. E., and Osteryoung, K. W. (2003). ARC5, a cytosolic dynamin-like protein from plants, is part of the chloroplast division machinery. Proc. Natl. Acad. Sci. U.S.A. 100, 4328-4333. doi: 10.1073/pnas.0530206100

Giegé, P., Sweetlove, L. J., Cognat, V., and Leaver, C. J. (2005). Coordination of nuclear and mitochondrial genome expression during mitochondrial biogenesis in Arabidopsis. Plant Cell 17, 1497-1512. doi: 10.1105/tpc.104. 030254

Gray, M. W., Lang, B. F., and Burger, G. (2004). Mitochondria of protists. Annu. Rev. Genet. 38, 477-524. doi: 10.1146/annurev.genet.37.110801.142526

Gurdon, C., Svab, Z., Feng, Y., Kumar, D., and Maliga, P. (2016). Cell-tocell movement of mitochondria in plants. Proc. Natl. Acad. Sci. U.S.A. 113, 3395-3400. doi: 10.1073/pnas.1518644113

Hartmann, N., Reichwald, K., Wittig, I., Drose, S., Schmeisser, S., Luck, C., et al. (2011). Mitochondrial DNA copy number and function decrease with age in the short-lived fish Nothobranchius furzeri. Aging Cell 10, 824-831. doi: 10.1111/j.1474-9726.2011.00723.x

Higa, T., and Wada, M. (2016). Chloroplast avoidance movement is not functional in plants grown under strong sunlight. Plant Cell Environ. 39, 871-882. doi: $10.1111 /$ pce. 12681

Holloszy, J. O. (1967). Biochemical adaptations in muscle. Effects of exercise on mitochondrial oxygen uptake and respiratory enzyme activity in skeletal muscle. J. Biol. Chem. 242, 2278-2282.

Howe, C. J., Barbrook, A. C., Koumandou, V. L., Nisbet, R. E. R., Symington, H. A., and Wightman, T. F. (2002). Evolution of the chloroplast genome. Philos. Trans. R. Soc. B. 358, 99-107. doi: 10.1098/rstb.2002.1176

Huang, L. R., Cox, E. C., Austin, R. H., and Sturm, J. C. (2004). Continuous particle separation through deterministic lateral displacement. Science 304, 987-990. doi: 10.1126/science. 1094567

Iborra, F. J., Kimura, H., and Cook, P. R. (2004). The functional organization of mitochondrial genomes in human cells. BMC Biol. 2:9. doi: 10.1186/17417007-2-9

Inuda, N., and Wildermuth, M. C. (2004). Novel tissue preparation method and cell-specific marker for laser microdissection of Arabidopsis mature leaf. Planta 221, 9-16. doi: 10.1007/s00425-004-1427-y 
Irrcher, I., Adhihetty, P. J., Sheehan, T., Joseph, A. M., and Hood, D. A. (2003). $\operatorname{PPAR} \gamma$ co-activator- $1 \alpha$ expression during thyroid hormone- and contractile activity-induced mitochondrial adaptations. Am. J. Physiol. Cell Physiol. 284, C1669-1677. doi: 10.1152/ajpcell.00409.2002

Itoh, R., Takahashi, H., Toda, K., Kuroiwa, H., and Kuroiwa, T. (1996). Aphidicolin uncouples the chloroplast division cycle from the mitotic cycle in the unicellular red alga Cyanidioschyzon merolae. Eur. J. Cell Biol. 71, 303-310.

Itzkovitz, S., Lyubimova, A., Blat, I. C., Maynard, M., van Es, J., Lees, J., et al. (2012). Single-molecule transcript counting of stem-cell markers in the mouse intestine. Nature Cell Biol. 14, 106-114. doi: 10.1038/ncb2384

Karnkowska, A., Vacek, V., Zubáčová, Z., Treitli, S. C., Petrželková, R., Eme, L., et al. (2016). A eukaryote without a mitochondrial organelle. Curr. Biol. 26, 1274-1284. doi: 10.1016/j.cub.2016.03.053

Karr, J. R., Sanghvi, J. C., Macklin, D. N., Gutschow, M. V., Jacobs, J. M., Bolival, B., et al. (2012). A whole-cell computational model predicts phenotype from genotype. Cell 150, 389-401. doi: 10.1016/j.cell.2012.05.044

Kleiber, M. (1947). Body size and metabolic rate. Physiol. Rev. 27, 511-541.

Kowald, A., and Kirkwood, T. B. L. (2011). Evolution of the mitochondrial fusionfission cycle and its role in aging. Proc. Natl. Acad. Sci. U.S.A. 108, 10237-10242. doi: 10.1073/pnas.1101604108

Kubínová, Z., Janáček, J., Lhotáková, Z., Kubínová, L., and Albrechtová, J. (2014). Unbiased estimation of chloroplast number in mesophyll cells: advantage of a genuine three-dimensional approach. J. Exp. Bot. 65, 609-620. doi: $10.1093 /$ jxb/ert407

Kukat, C., Wurm, C. A., Spåhr, H., Falkenberg, M., Larsson, N. G., and Jakobs, S. (2011). Super-resolution microscopy reveals that mammalian mitochondrial nucleoids have a uniform size and frequently contain a single copy of mtDNA. Proc. Natl. Acad. Sci. U.S.A. 108, 13534-13539. doi: 10.1073/pnas.1109263108

Kuroiwa, T. (1991). The replication, differentiation, and inheritance of plastids with emphasis on the concept of organelle nuclei. Int. Rev. Cytol. 128, 1-62. doi: 10.1016/S0074-7696(08)60496-9

Lamppa, G. K., Elliot, L. V., and Bendich, A. J. (1980). Changes in chloroplast number during development of pea (Pisum sativum). Plant Physiol. 64, 126-130. doi: 10.1104/pp.64.1.126

Lee, D. Y., and Clayton, D. A. (1998). Initiation of mitochondrial DNA replication by transcription and r-loop processing. J. Biol. Chem. 273, 30614-30621. doi: $10.1074 /$ jbc. 273.46 .30614

Legros, F., Malka, F., Franchon, P., Lombès, A., and Rojo, M. (2004). Organization and dynamics of human mitochondrial DNA. J. Cell Sci. 117, 2653-2662. doi: $10.1242 /$ jcs.01134

Leigh-Brown, S., Enriquez, J. A., and Odom, D. T. (2010). Nuclear transcription factors in mammalian mitochondria. Genome Biol. 11, 215. doi: 10.1186/gb2010-11-7-215

Li, H., Bai, D., Hu, Y., Kuang, T., and Lin, J. (2001). Differences between the number and structure of chloroplasts in leaves and in non-leaf organs of wheat. Belg. J. Bot. 134, 121-126.

Logan, D. C. (2007). Annual Plant Reviews: Plant Mitochondria. Oxford: Blackwell Publishing Ltd.

López-Juez, E. (2007). Plastid biogenesis, between light and shadows. J. Exp. Bot. 58, 11-26. doi: 10.1093/jxb/erl196

Lu, Y., Rolland, S. G., and Conradt, B. (2011). A molecular switch that governs mitochondrial fusion and fission mediated by the BCL2-like protein CED-9 of Caenorhabditis elegans. Proc. Natl. Acad. Sci. U.S.A. 108, E813-E822. doi: 10.1073/pnas. 1103218108

Lynch, M. (2006). The origins of eukaryotic gene structure. Mol. Biol. Evol. 23, 450-468. doi: 10.1093/molbev/msj050

Lynch, M. (2011). The lower bound to the evolution of mutation rates. Genome Biol. Evol. 3, 1107-1118. doi: 10.1093/gbe/evr066

Lynch, M., Koskella, B., and Schaack, S. (2006). Mutation pressure and the evolution of organelle genomic architecture. Science 311, 1727-1730. doi: $10.1126 /$ science. 1118884

Lynch, M., and Marinov, G. (2016). The bioenergetic costs of a gene. Proc. Natl. Acad. Sci. U.S.A. 112, 11690-11695. doi: 10.1073/pnas. 1514974112

Marinos, E. (1985). The number of mitochondria in Xenopus laevis ovulated oocytes. Cell Differ. 16, 139-143. doi: 10.1016/0045-6039(85)90527-5

Mattiasson, G. (2004). Flow cytometric analysis of isolated liver mitochondria to detect changes relevant to cell death. Cytometry A 60, 145-154. doi: 10.1002/cyto.a.20024
McBride, H. M., Neuspiel, M., and Wasiak, S. (2006). Mitochondria: more than just a powerhouse. Curr. Biol. 16, R551-560. doi: 10.1016/j.cub.2006.06.054

McCauley, D. E. (2013). Paternal leakage, heteroplasmy, and the evolution of plant mitochondrial genomes. New Phytol. 200, 966-977. doi: 10.1111/nph.12431

Moller, S. G. (2004). Plastids. Oxford: Blackwell Publishing Ltd.

Moraes, C. T. (2001). What regulates mitochondrial DNA copy number in animal cells? Trends Genet. 17, 199-205.

Mower, J. P., Case, A. L., Floro, E. R., and Willis, J. H. (2012). Evidence against equimolarity of large repeat arrangements and a predominant master circle structure of the mitochondrial genome from a monkeyflower (Mimulus guttatus) lineage with cryptic CMS. Genome Biol. Evol. 4, 670-686. doi: 10.1093/gbe/evs042

Okie, J. G., Smith, V. H., and Martin-Cereceda, M. (2016). Major evolutionary transitions of life, metabolic scaling and the number and size of mitochondria and chloroplasts. Proc. R. Soc. B. 283, 20160611. doi: 10.1098/rspb.2016.0611

Palmer, J. D., and Herbon, L. A. (1988). Plant mitochondrial DNA evolved rapidly in structure, but slowly in sequence. J. Mol. Evol. 28, 87-97. doi: 10.1007/BF02143500

Palmer, J. D., and Shields, C. R. (1984). Tripartite structure of the Brassica campestris mitochondrial genome. Nature 307, 437-440. doi: 10.1038/307437a0

Palumbi, S. R., Cirpriano, F., and Hare, M. P. (2001). Predicting nuclear gene coalescence from mitochondrial data: the three-times rule. Evolution 44, 859-868. doi: 10.1554/0014-3820(2001)055[0859:PNGCFM]2.0.CO;2

Posakony, J. W., England, J. M., and Attardi, G. (1977). Mitochondrial growth and division during the cell cycle in HeLa cells. J. Cell Biol. 74, 468-491. doi: 10.1083/jcb.74.2.468

Preuten, T., Cincu, E., Fuchs, J., Zosche, R., Liere, K., and Börner, T. (2010). Fewer genes than organelles: extremely low and variable gene copy numbers in mitochondria of somatic plant cells. Plant J. 64, 948-959. doi: 10.1111/j.1365313X.2010.04389.x

Rafelski, S. M., Viana, M. P., Zhang, Y., Chan, Y.-H., M., Thorn, K. S., Yam, P., et al. (2012). Mitochondrial network size scaling in budding yeast. Science 338, 822-824. doi: $10.1126 /$ science. 1225720

Rawsthorne, S. (2002). Carbon flux and fatty acid synthesis in plants. Prog. Lipid Res. 41, 182-196. doi: 10.1016/S0163-7827(01)00023-6

Robin, E. D., and Wong, R. (1988). Mitochondrial DNA molecules and virtual number of mitochondria per cell in mammalian cells. J. Cell. Physiol. 136, 507-513. doi: $10.1002 / j c p .1041360316$

Rokas, A., Ladoukakis, E., and Zouros, E. (2003). Animal mitochondrial DNA revisited. Trends Ecol. Evol. 18, 411-417. doi: 10.1016/S0169-5347(03)00125-3

Rossier, M. F. (2006). T channels and steroid biosynthesis: in search of a link with mitochondria. Cell Calcium 40, 155-164. doi: 10.1016/j.ceca.2006.04.020

Ruberti, C., Barizza, E., Bodner, M., La Rocca, N., De Michelle, R., Carimi, F., et al. (2014). Mitochondria change dynamics and morphology during grapevine leaf senescence. PLoS ONE 9:E102012. doi: 10.1371/journal.pone.0102012

Satoh, M., and Kuroiwa, T. (1991). Organization of multiple nucleiods and DNA molecules in mitochondria of a human cell. Exp. Cell Res. 196, 137-140. doi: 10.1016/0014-4827(91)90467-9

Schmitz-Linneweber, C., and Small, I. (2008). Pentatricopeptide repeat proteins: a socket set for organelle gene expression. Trends Plant Sci. 13, 663-670. doi: 10.1016/j.tplants.2008.10.001

Scott, N. S., and Possingham, J. V. (1980). Plastid replication and development in the life cycle of higher plants. Annu. Rev. Plant Physiol. 31, 113-129. doi: 10.1146/annurev.pp.31.060180.000553

Scott, N. S., and Possingham, J. V. (1983). Changes in chloroplast DNA levels during growth of spinach leaves. J. Exp. Bot. 34, 1756-1767. doi: 10.1093/ $\mathrm{jxb} / 34.12 .1756$

Solieri, L. (2010). Mitochondrial inheritance in budding yeasts: towards an integrated understanding. Trends Microbiol. 18, 521-530. doi: 10.1016/ j.tim.2010.08.001

Stoecker, D. K., and Silver, M. W. (1990). Replacement and aging of chloroplasts in Strombidium capitatum (Ciliophora: Oligotrichida). Mar. Biol. 107, 491-502. doi: 10.1007/BF01313434

Suthers, P. F., Dasika, M. S., Kumar, V. S., Denisov, G., Glass, J. I., and Marana, C. D. (2009). A genome-scale metabolic reconstruction of Mycoplasma genitalium iPS189. PLoS Comput. Biol. 5:e1000285. doi: 10.1371/journal.pcbi.1000285

Suyama, Y., and Bonner, W. D. (1966). DNA from plant mitochondria. Plant Physiol. 41, 383-388. doi: 10.1104/pp.41.3.383 
Terasawa, K., and Sato, N. (2005). Visualization of plastid nucleoids in situ using the PEND-GFP fusion protein. Plant Cell Physiol. 46, 649-660. doi: $10.1093 / \mathrm{pcp} / \mathrm{pci0} 0$

Thyssen, G., Svab, Z., and Maliga, P. (2012). Cell-to-cell movement of plastids in plants. Proc. Natl. Acad. Sci. U.S.A. 109, 2439-2443. doi: 10.1073/ pnas.1114297109

van Wijk, K. J. (2004). Plastid proteomics. Plant Physiol. Biochem. 42, 963-977. doi: 10.1016/j.plaphy.2004.10.015

van Wijk, K. J., and Baginsky, S. (2011). Plastid proteomics in higher plants: current state and future goals. Plant Physiol. 155, 1578-1588. doi: 10.1104/ pp.111.172932

Veltri, K. L., Espiritu, M., and Singh, G. (1990). Distinct genomic copy number in mitochondria of different mammalian organs. J. Cell. Physiol. 143, 160-164. doi: $10.1002 /$ jcp. 1041430122

Ventura-Clapier, R., Garnier, A., and Veksler, V. (2008). Transcriptional control of mitochondrial biogenesis: the central role of PGC-1 $\alpha$. Cardiovasc. Res. 79, 208-217. doi: 10.1093/cvr/cvn098

Virbasius, J. V., and Scarpulla, R. C. (1994). Activation of the human mitochondrial transcription factor A gene by nuclear respiratory factors: a potential regulatory link between nuclear and mitochondrial gene expression in organelle biogenesis. Proc. Natl. Acad. Sci. U.S.A. 91, 1309-1313. doi: 10.1073/pnas.91.4.1309

Visser, W., van Spronsen, E. A., Nanninga, N., Pronk, J. T., Gijs Kunen, J., and van Dijken, J. P. (1995). Effects of growth conditions on mitochondrial morphology in Saccharomyces cerevisiae. Antonie Leeuwenhoek 67, 243-253. doi: $10.1007 / \mathrm{BF} 00873688$
Weisner, R. J., Ruegg, J. C., and Morano, I. (1992). Counting target molecules by exponential polymerase chain reaction: copy number of mitochondrial DNA in rat tissues. Biochem. Biophys. Res. Comm. 183, 553-559. doi: 10.1016/0006291X(92)90517-O

Williamson, D. H., and Fennell, D. J. (1979). Visualization of yeast mitochondrial DNA with the fluorescent stain "DAPI". Methods Enzymol. 56, 728-733 doi: 10.1016/0076-6879(79)56065-0

Wu, Z., Puigserver, P., Andersson, U., Zhang, C., Adelmant, G., Mootha, V., et al. (1999). Mechanisms controlling mitochondrial biogenesis and respiration through the thermogenic coactivator PGC-1. Cell 98, 115-124. doi: 10.1016/S0092-8674(00)80611-X

Zoschke, R., Liere, K., and Börner, T. (2007). From seedling to mature plant: Arabidopsis plastidal genome copy number, RNA accumulation and transcription are differentially regulated during leaf development. Plant J. 50, 710-722. doi: 10.1111/j.1365-313X.2007.03084.x

Conflict of Interest Statement: The author declares that the research was conducted in the absence of any commercial or financial relationships that could be construed as a potential conflict of interest.

Copyright (c) 2016 Cole. This is an open-access article distributed under the terms of the Creative Commons Attribution License (CC BY). The use, distribution or reproduction in other forums is permitted, provided the original author(s) or licensor are credited and that the original publication in this journal is cited, in accordance with accepted academic practice. No use, distribution or reproduction is permitted which does not comply with these terms. 